
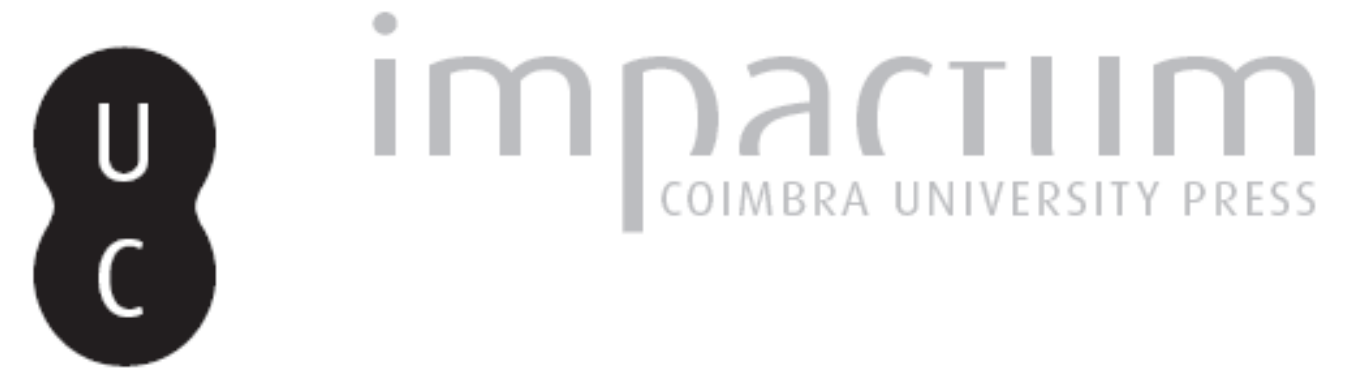

\title{
Investigações da invenção e reinvenção da memória
}

Autor(es): $\quad$ Gil, Bruno

Publicado por: Editorial do Departamento de Arquitetura

URL persistente:

URI:http://hdl.handle.net/10316.2/37329

DOI:

DOI:http://dx.doi.org/10.14195/1647-8681_3_14

Accessed : $\quad$ 26-Apr-2023 08:18:24

A navegação consulta e descarregamento dos títulos inseridos nas Bibliotecas Digitais UC Digitalis, UC Pombalina e UC Impactum, pressupõem a aceitação plena e sem reservas dos Termos e Condições de Uso destas Bibliotecas Digitais, disponíveis em https://digitalis.uc.pt/pt-pt/termos.

Conforme exposto nos referidos Termos e Condições de Uso, o descarregamento de títulos de acesso restrito requer uma licença válida de autorização devendo o utilizador aceder ao(s) documento(s) a partir de um endereço de IP da instituição detentora da supramencionada licença.

Ao utilizador é apenas permitido o descarregamento para uso pessoal, pelo que o emprego do(s) título(s) descarregado(s) para outro fim, designadamente comercial, carece de autorização do respetivo autor ou editor da obra.

Na medida em que todas as obras da UC Digitalis se encontram protegidas pelo Código do Direito de Autor e Direitos Conexos e demais legislação aplicável, toda a cópia, parcial ou total, deste documento, nos casos em que é legalmente admitida, deverá conter ou fazer-se acompanhar por este aviso.

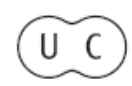




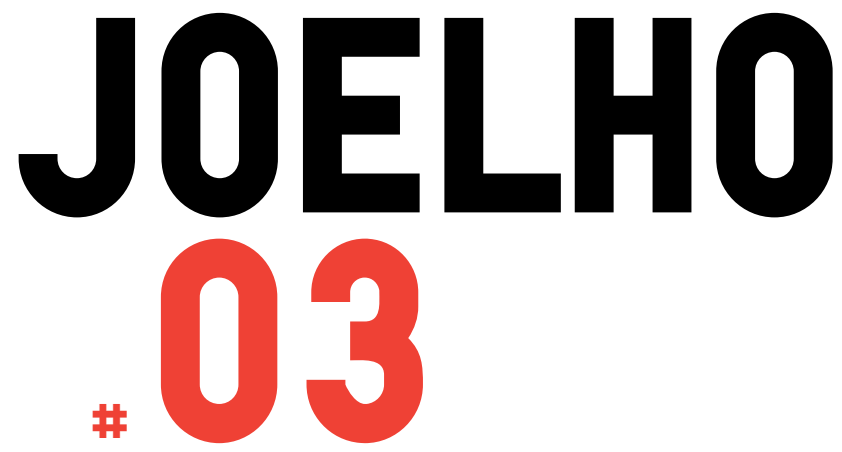

\section{VIAGEM-MEMÓRIAS: APRENDIZAGENS DE ARQUITECTURA}

Coordenação:

Alexandre Alves Costa

Domingos Tavares

Exposição Viagem

Exposição Memórias

Luis Mansilla

Alexandre Alves Costa

Domingos Tavares

SCA FoL DiNG
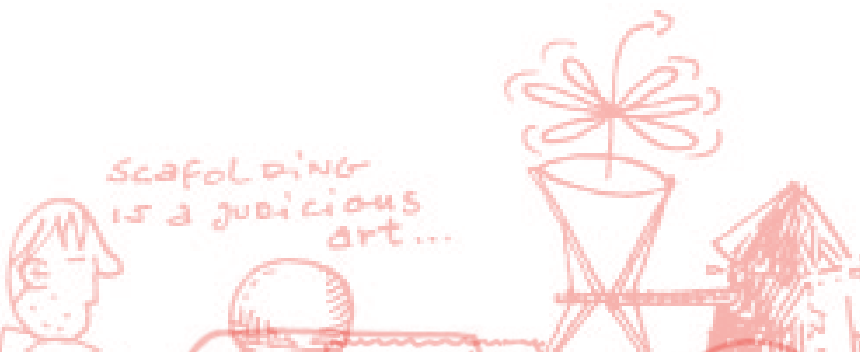

Jorge Figueira

José Miguel Rodrigues

José António Bandeirinha José Fernando Gonçalves

Paulo Providência

Gonçalo Canto Moniz Armando Rabaça

Patrícia Miguel

Bruno Gil

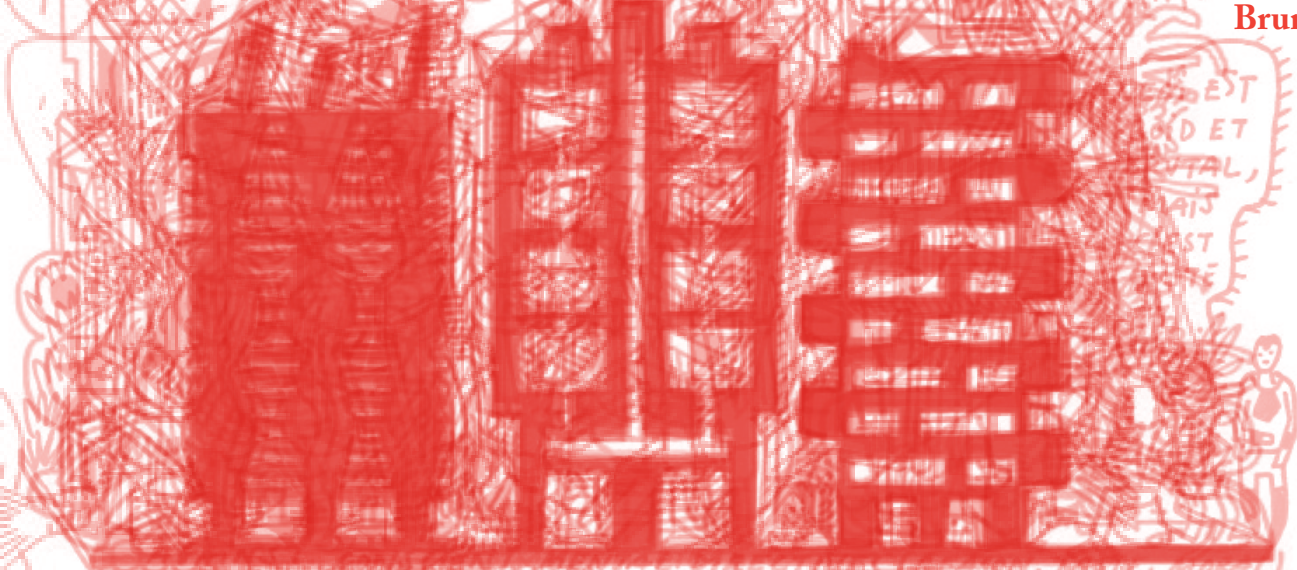

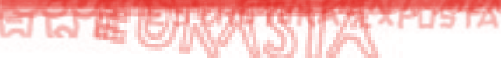


Bruno Gil

Investigações da

invenção e reinvenção

da memenória

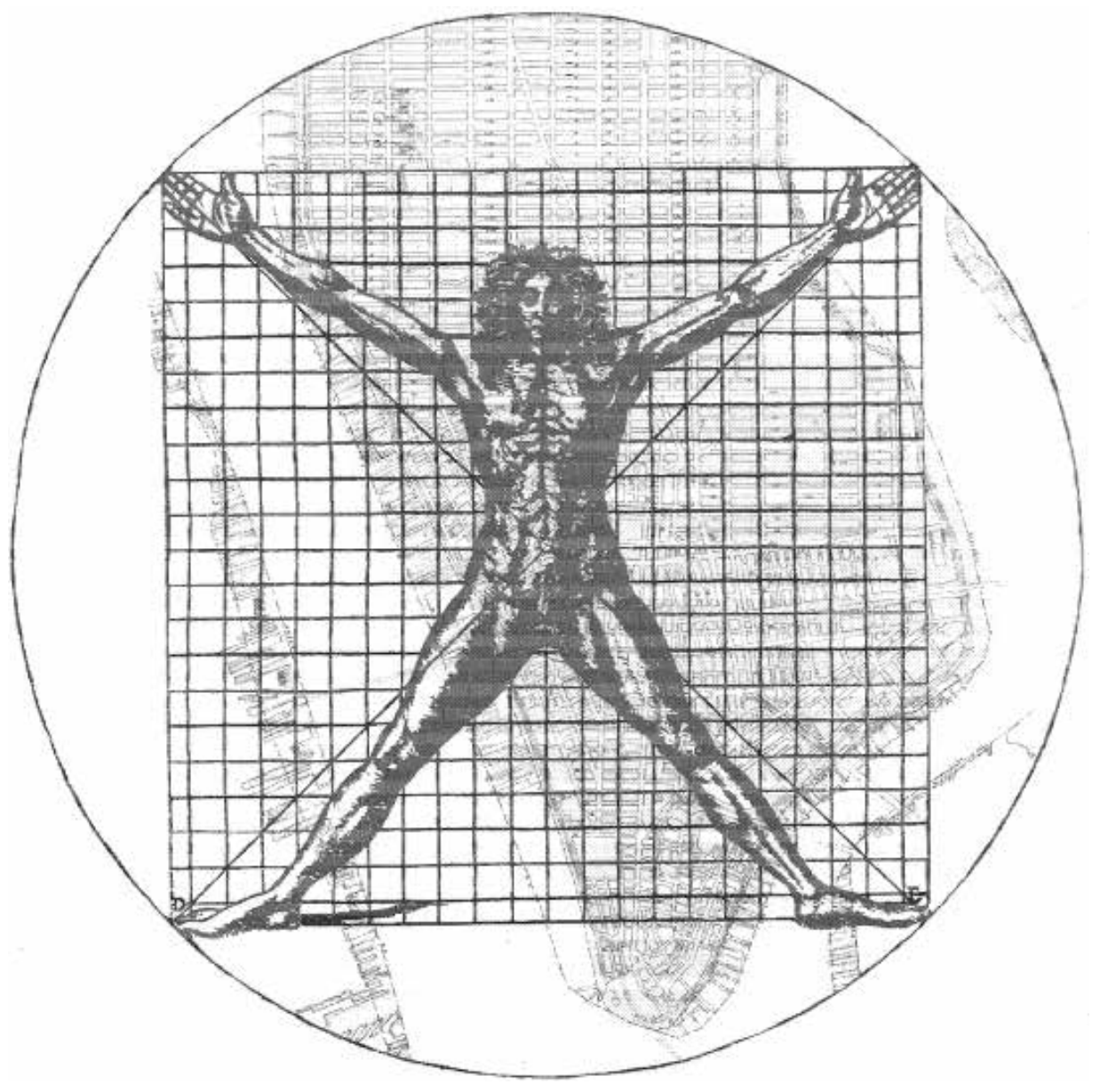

$\bar{c}$ 


\section{Although we recognize research is integral to architecture and its education, we are often unclear what constitutes original architectural research, and how research might best be practiced today.}

(Philips, 2009, p.10)

A problematização em torno da investigação na arquitectura decorre das incertezas, naturais do seu tempo curto. Se na arquitectura o projecto tem 500 anos, a investigação não tem mais que 50. É a partir da década de 1960 que se geram centros de arquitectura, que também eram de investigação. Esses lugares eram híbridos de aprendizagem e investigação onde a memória era alvo de invenção e reinvenção. Apesar do consenso generalizado quanto à pertinência do acto de investigar, as incertezas são ainda mais significativas do que as certezas, no que diz respeito à sua prática e nas relações com o método que se tem como consensual - o projecto. Importa, assim, colocar a questão tão corrente no actual contexto académico: que investigação é que a arquitectura quer?

Naturalmente, surge a dúvida sobre a especificidade do acto de investigar em arquitectura ou, pelo contrário, a assunção de contornos e características da investigação doutras disciplinas. E uma vez mais vem ao de cima a relação entre arte e ciência, onde as hesitações disciplinares eram evidentes nas vanguardas do século $\mathrm{xx}$, no embate com a modernidade, expressas nas experiências da Bauhaus ou da Vkhutemas. Admitir a existência de especificidades, implica uma caracterização e definição de investigação, tanto no tipo como na escala, aferindo sempre a validade de um enquadramento com a arquitectura.

Consequentemente, testar-se-á a hipótese de que, por um lado, a investigação dita fundamental em arquitectura promove uma contribuição iminentemente intra-disciplinar e que, por outro lado, a investigação aplicada, visando o desenvolvimento, tende para um compromisso extra-disciplinar. Para contribuir sobre o que poderá representar em arquitectura, a adopção e o exercício consciente destes tipos de pesquisa, iniciaremos um processo retrospectivo, que passará sobre experiências de ensino-aprendizagem e de investigação, tidas como centrais, e até embrionárias, para a discussão. Partindo de especificidades da Bauhaus, aludindo a estudos do Centre for Land Use and Built Form Studies ou do movimento Design Methods e chegando ao Institute for Architecture and Urban Studies, a selecção destes casos considera que se alguns partiam de uma perspectiva fundamental, outros pendiam para uma investigação aplicada e de desenvolvimento, ou chegavam a admitir, num só projecto, contribuições tanto no nível fundamental como aplicado.

\section{Sobre o tipo e a escala da investigação}

Efectuar uma aproximação às experiências daqueles centros de estudos em arquitectura, através da lente da investigação, exige enfrentar diversas perplexidades, ensaiando alguns esclarecimentos sobre a adopção para a arquitectura de uma tipologia de níveis de pesquisa, 
originária das ciências exactas, e sobre os reflexos de uma tendencial especialização e ramificação dos conhecimentos, na escala do campo de acção, que vai do geral ao específico.

Destrinçando diferenças tanto no tipo como na escala da investigação, Nuno Portas introduz em 1964, as definições trazidas para a arquitectura, por Llewellyn-Davies, então director da Bartlett. Por ordem crescente de generalidade, identifica a prática avançada; o trabalho de desenvolvimento; a investigação aplicada; e a investigação fundamental (2008, p.73). ${ }^{1}$

Se Portas exemplifica a prática avançada com o estudo de um sistema de elementos pré-fabricados, na investigação fundamental alude aos estudos básicos provenientes da teoria e estética da arquitectura. Colocase a hipótese de um acto de investigação dito fundamental englobar maior generalidade e um aplicado maior especificidade. Esta interpretação parece contrária ao que acontece nas ciências naturais, quando por exemplo o estudo de uma célula (considerado investigação fundamental) parece corresponder a uma maior especificidade em relação ao estudo do corpo. $\bigcirc$ que pode indicar que a especialização é variável independente do tipo de investigação e verificar-se em qualquer um dos níveis, fundamental ou aplicado.

Sobre o desenvolvimento das ciências humanas, Balandier considerava na sua reflexão prospectiva ${ }^{2}$ que será "de conhecimentos polivalentes e duma certa disponibilidade intelectual, mais do que de conhecimentos especializados, que importará dotar as gerações ascendentes." (Balandier, 1963, p.373) Contudo, reconhece a especialização como oportunidade para a fertilização interdisciplinar.

Ora, no contexto de uma super-especialização, o que Eisenman vem questionando, e que abordou no EURAU ${ }^{3}$ de 2008, é que a ameaça não virá da fertilização mas do excessivo deslumbre pela componente. A visão da parte com o todo e o projecto sintético estão em risco:

"Leon Battista Alberti said a house is a small city and a city is a large house. [...] That relation has sustained architecture for five hundred years. Now it is under attack. People [...] no longer believe that it's necessary. [...] The reason for this is that we can now in computation, in the digital, we can make all sorts of component relationships and we can manipulate them into all sorts of value free wholes, that look fantastic, each one of them different and none of them saying anything." (Eisenman, 2008)

Mas como Picon relembra, Viollet-le-Duc já em Histoire d'un Dessinateur, exercitava mimetismos da estrutura óssea para mecanismos, ou componentes (Fig.l) (Picon, 1999). Pelo que a justificação não será específica do digital, mas da adopção da tecnologia e sua adaptação à disciplina.

\section{Da ideia ao produto}

As aproximações entre arte e ciência têm sido alvo de inúmeras considerações, tanto pelas questões mais fracturantes entre as culturas humanista e científica, como nos relembra C.P. Snow (1961), como por 
contaminações entre campos disciplinares que vêm acontecendo desde as suas origens. $O$ contexto tecnológico de reprodutibilidade, que motivou grande parte das experiências formativas da Bauhaus, ocasionou no período curto da sua existência uma progressiva adaptação do que apelidaremos de princípios.

No manifesto de 1919, os princípios de Gropius para a escola eram claramente guiados por uma ordem original, colectiva e matricial. Na ideia expressionista o espírito era bem mais cristalino do que seria o l'esprit nouveau corbusiano. Noutro texto do mesmo ano, alertava que "quando as ideias se tornam compromissos, morrem." (Gropius et al., 1970, p.46) e que as linhas divisórias entre sonho e realidade devem ser preservadas porque o encanto da fantasia é mais importante do que toda a técnica. $O$ desejo vincado de espiritualidade nos princípios da escola e que teria o seu devido prolongamento com Itten naqueles primeiros anos de Weimar, seria concretizado em experiências de investigação fundamental, como a formalização de uma "gramática da cor", tão evidente nos estudos básicos do Vorkurs e nas teorias da forma de Kandinsky.

No ano da passagem para Dessau, os princípios adaptam-se a outra ordem. Em "Os princípios de produção da Bauhaus" de 1926, dificilmente encaixaria a ilustração de Feininger. Aí os princípios são protótipos de produtos para a industrialização em massa. Gropius evidencia uma inclinação para o produto, mais que para a ideia e tendencialmente visa uma investigação aplicada. Com Hannes Meyer, enquanto director do novo departamento de arquitectura, a tendência passa a certeza. Intitulando-se como um convicto "marxista científico", Meyer introduz na Bauhaus os princípios de uma ciência positivista ao promover encontros com Carnap ou Neurath, do Círculo de Viena (Galison, 1990). Para Meyer construir não era um processo estético. Em "Construir" de 1928, o que prevalece é a lógica normativa do produto num socialismo económico: "Todas as coisas deste mundo são um produto da fórmula: (função por economia)" (Meyer, 1970, p.117). Meyer foi um dos signatários da Declaração de La Sarraz de 1928, enquanto manifesto introdutório aos CIAM, onde ficaria expressa a aplicação da arquitectura ao produto, ao colectivo, à objectividade e à economia.

A recuperação do corte da segunda guerra e a tecnologia computacional daí emergente imprimem novo ritmo na investigação e nas relações com a aprendizagem. A conferência sobre educação de Oxford de 1958 aproxima a investigação científica da arquitectura. Para Leslie Martin o enquadramento do ensino da arquitectura na universidade introduz níveis avançados de investigação, que deverão ser inteligentemente adoptados de forma fundamental, não só como complemento, mas também como avanço da teoria: "Research is the tool by which theory is advanced. Without it, teaching can have no direction and thought no cutting edge" (Martin, 1958). Mas a fundação do Centre for Land Use and Built Form Studies (LUBFS) em Cambridge, por Martin

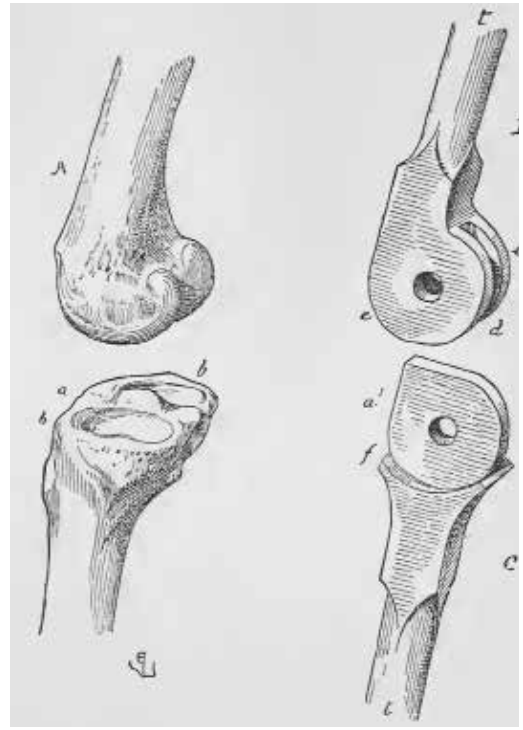

1. Componentes mecânicos a partir de mimetismos ósseos. Viollet-le-Duc.

[Viollet-le-Duc, E.-E., 1879, Histoire d'un dessinateur, J. Hetzel, p.132] 


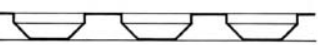

2. Formas e anti-formas para a mesma área de terreno, volume construído e profundidade. LUBFS. [Martin, L.; March, L. (eds.), 1972 Urban Space and Structures, Cambridge University Press, p. 20] e March, tem uma missão clara no que respeita a uma investigação aplicada. Os estudos desenvolvidos (Fig.2) visam respostas completas e aplicadas para um caso específico, o Plano Whitehall para Londres:

"Estes estudos de Leslie Martin em vez de se proporem como revisões da prática profissional ou, ainda menos, da teoria da arquitectura, apontam no sentido de confrontarmos as questões colocadas pela prática profissional com o pensamento racional e o especulativo." (Krüger, 2005, p.27)

Pelo que se considera que a actividade de investigação será mais fundamental nos princípios preconizados do que na sua aplicação em contexto.

Em sentido contrário, nas linhas gerais do movimento Design Methods, a investigação é aplicada nos princípios. E continua aplicada até aos resultados. Aqui a arquitectura ultrapassa a linha divisória entre arte e ciência.

Sobre o panorama da investigação e da organização dos centros de investigação, Herbert Simon alerta que grande percentagem emula os métodos dos poucos que realmente chegam à invenção, o que denomina como o fenómeno NIH - Not Invented Here (Simon, 1991, p.130). Na cultura científica emular implicará desenhar sobre o círculo que foi desenhado originalmente, o que encaixa nas práticas da ciência normal (Kuhn, 2009).

$\mathrm{Na}$ cultura arquitectónica, dificilmente o desenho do círculo será coincidente com o anterior, enquanto cosa mentale, onde reescrever a memória é também um processo retrospectivo, com base nos préconceitos, e prospectivo partindo de conceitos para o futuro.

"A nossa capacidade para imaginar eventuais acontecimentos também depende da aprendizagem e da recordação, e é o fundamento do raciocínio e da navegação imaginária do futuro e, de uma forma mais geral, da criação de soluções inovadoras para um problema."

(Damásio, 2010, p.169)

Consequentemente, da ideia ao produto, como resolver ambiguidades entre análise e intuição, entre conhecimento colectivo e individual? Passará por as deixar em aberto ou por ceder à tentação de as fechar? Muito dependerá da definição do problema, que implicará a natureza dos métodos e condicionará as soluções. Como na reflexão de Bergson, sobre a duração e o método, formular o problema não é simplesmente descobrir, também é inventar (1975, p.22).

\section{Do Instituto às ruas}

O que o Institute for Architecture and Urban Studies (IAUS, mais conhecido como "o Instituto") introduz como estratégia de acção, é a assunção de que o processo de investigação, do fundamental ao desenvolvimento, deve ser interpretado como um só. Peter Eisenman, o grande impulsionador do Instituto, em 1967 em Nova Iorque, via-o como uma casa que estava a meio caminho entre a escola e a profissão. E esta visão, da informalidade de uma casa e formalidade de um instituto, era clara nos objectivos incluídos no cartaz de divulgação: 
"As an alternative to academic studies and present practices of the profession, the Institute combines teaching, research, and development into one process. To this end it coordinates the resources of the university, the museum, and public and private planning agencies." (apud Frank, 2010, p.4)

Eisenman visava um híbrido da investigação de Cambridge com a especulação da Architectural Association (AA). Com efeito, a experiência de investigação académica que trazia de Cambridge, motivada por Leslie Martin e formalizada com o mentor Colin Rowe no doutoramento The Formal Basis of Modern Architecture, fora mediada pela sua assiduidade na vida da AA.

O logótipo escolhido para o IAUS sobrepunha o Homem vitruviano maneirista à grelha e, por último, ao mapa de Manhattan (Fig.3). Se a sobreposição surge algo enigmática, é claro o enfoque na cidade, num contexto urbano e social marcado pelo reconhecimento do dinamismo participativo, personalizado por Jane Jacobs. O Instituto actuava na cidade e fazia parte da cidade. $O$ no 8 , em frente ao Bryant Park e à Biblioteca Pública de Nova Iorque, era uma porta anónima indiferenciada na rua, de resto tal como o é o no 36 da Architectural Association. Pelo que a ambição não era já a de resolver a totalidade, como um novo espírito moderno, mas partir para uma investigação contextual e de mediação. Ocupando o último piso do edifício, os gabinetes individuais organizavam-se no perímetro de um espaço central, como se funcionasse a duas velocidades: a do individual, respeitando a liberdade do investigador e a do colectivo, quando os investigadores se enfrentavam no espaço central - o Instituto era lugar de debate (Fig.4).

Os estudos eram desenvolvidos por equipas e evidentemente, como uma boa equipa, vestiam literalmente a camisola (Fig.5). Entre os presentes, destaca-se a presença de Duarte Cabral de Mello como investigador assistente de 1970 a 1972:

“Durante esses anos, participei nalguns projectos já em curso e tive o incentivo generoso e exigente para que fizesse as minhas inquirições, autónomas e independentes. Uma boa parte delas foram integradas no Generative Design Program, que desenvolvi em parceria com os professores Eisenman, Diana Agrest e Mario Gandelsonas, para o US National Institute of Mental Health." (Mello, 2007, p.IV)

Os programas de investigação aplicada e desenvolvimento também eram fonte de receita. Ao mesmo tempo que permitiam a continuidade da investigação aplicada, viabilizavam a investigação fundamental independente, condição essencial para a invenção, e que se traduzia na filosofia do Instituto enquanto espaço de problematização teórica e crítica. Assim surge a motivação para a publicação de uma revista. Revista, para a qual Cabral de Mello teria uma contribuição significativa com um quadro de tons quentes laranja avermelhado (Fig.6). Num jogo de letras pós-moderno, com influências estruturalistas, podia-se ler ó de exclamação, ócio, cio, ódio e dio como deus (Frank, 2010, p.42).

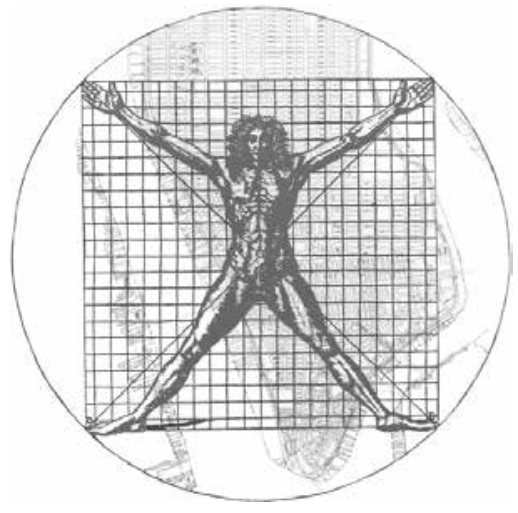

3. Logótipo do Instituto.

[Mendini, A. (ed.), 1971, The City as an Artifact, Casabella, 359-360, p.9]

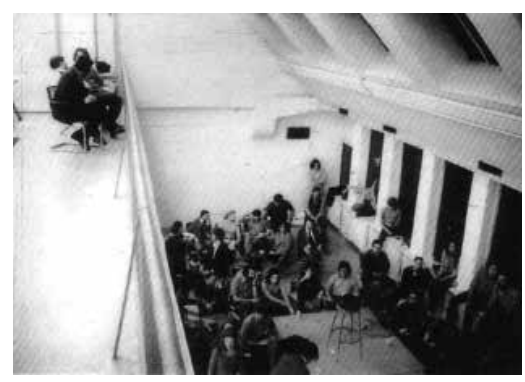

4. Vista do grande hall. Fotografia de Suzanne Frank. [Frank, S., 2010, IAUS, the Institute for Architecture and Urban Studies: an insider's memoir. AuthorHouse, p.31]

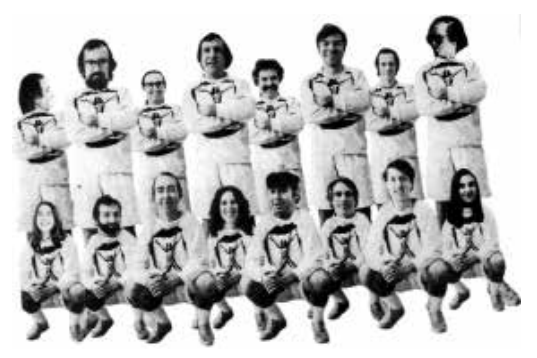

5. Elementos do Instituto equipados. Fila superior da esq. para a dir.: J. Rykwert, D. Cabral de Mello, M. Gandelsonas, K. Frampton, J. Mantel, G. Gale, T. Schumacher, S. Anderson. Fila inferior da esq. para a dir.: E. Cromley, R. Slutzky, W. Ellis, B. Spector, E. Ambasz, P. Eisenman, V. Caliandro, S. Frank.

[Mendini, A. (ed.), 1971, The City as an Artifact, Casabella, 359-360, p.101] 


\section{odio}

6. As múltiplas leituras do quadro de Duarte Cabral de Mello, 1968. [Frank, S., 2010, IAUS, the Institute for Architecture and Urban Studies: an insider's memoir. AuthorHouse, p.42]

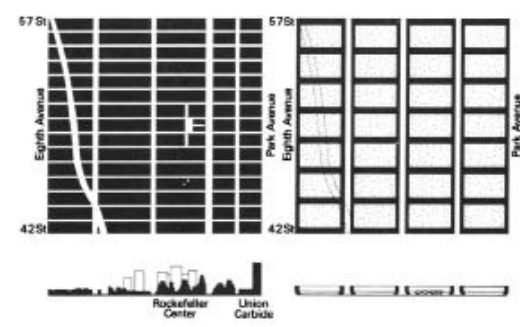

7. Grelha urbana de Nova lorque e proposta alternativa com formas em pátio com idêntica área construída e um terço de altura. LUBFS. [Martin, L.; March, L. (eds.), 1972, Urban Space and Structures, Cambridge University Press, p. 21]
Esta imagem antecipava a capa ícone da revista Oppositions, editada a partir de 1973 por Frampton, Eisenman e Gandelsonas, e desenhada por Vignelli.

Se o Instituto era lugar de publicações, era também lugar de exposições, trazendo pessoas ou temas centrais para o desenvolvimento teórico de então, como Rossi e Hejduk, ou o Construtivismo Russo, em 1971 - imprescindível na AA dos anos de 1970 - e, por último, era também lugar de aprendizagem.

A passagem de centro de investigação a ensino seria definitiva, passados dez anos da sua fundação, com o programa anual, Open Plan. Quatro conjuntos de aulas e seminários - Architecture, The City, The Arts, e Design - estruturariam o projecto educacional, financiado pelo National Endowment for the Humanities. $O$ ritmo diário das aulas nocturnas era marcado por um encontro interdisciplinar, tipo mesa redonda, em cada quatro semanas.

Mas a par desta abordagem mais performativa, importa focar nos projectos ali desenvolvidos e situá-los no que consideravam serem os objectivos de investigação e os compromissos disciplinares.

O Instituto acolheu a investigação desenvolvida por Koolhaas, durante a sua permanência enquanto professor visitante. É um exemplo de um vai e vem entre uma visão retrospectiva e prospectiva, como se a retroacção do manifesto Delirious New York representasse uma descoberta da cidade après-la-lettre. Numa revisão do livro, as palavras de Luís Santiago Baptista reflectem aquele vai e vem:

"Ao interceptar a abertura prospectiva com a herança retrospectiva, Koolhaas desconstrói as duas tendências dominantes da modernidade arquitectónica: por um lado, a vanguardista, com a sua vontade indómita de ruptura com o passado, e, por outro, a culturalista, com a sua necessidade premente de continuidade histórica." (Baptista, 2008)

Se Ian Hacking (1983) afirma que o laboratório é o lugar da criação de fenómeno usando dispositivos especialmente construídos para o efeito, Koolhaas cria uma Nova Iorque delirante no laboratório que é Manhattan e inventa o fenómeno. Manhattan, apesar de toda a evidência, é ainda realização imperfeita da "cultura da congestão".

No âmbito da investigação do LUBFS, Leslie Martin (1972) testara o teorema das formas e anti-formas sobre a grelha de Nova Iorque, admitindo que seria possível obter a mesma densidade com menor altura (Fig.7). Mas o factor espectacularização da congestão em altura advém de uma aleatoriedade permitida por uma terceira dimensão espontânea, num rigoroso plano bidimensional - um "caos rígido" (Koolhaas, 1994, p.20).

Tratando-se de um discurso dificilmente categorizável, e mesmo aceitando a consideração de Hanrot (2002, p.178) que se enquadra nos princípios de uma investigação experimental, parece certo que em Delirious New York o registo é fundamental e disruptivo. É tudo menos directo, quanto a uma aplicação ou implementação específica. 
Noutro prisma, os projectos realizados no Instituto através de financiamentos de entidades públicas ou privadas, perspectivavam uma investigação de desenvolvimento e implementação. Como exemplo, o projecto de habitação Low Rise High Density, em Brooklyn, surgiu com a colaboração dos arquitectos e o apoio financeiro da Corporação de Desenvolvimento Urbano de Nova Iorque.

Contudo, o projecto que melhor parece sintetizar a missão original do IAUS, por um processo uno da investigação fundamental ao desenvolvimento, terá sido o projecto On Streets (Fig.8). Financiado pelo Departamento de Habitação e Desenvolvimento Urbano de Washington D.C., confirmava a ênfase original na cidade como área de estudo. Sintetizava, a partir de um só objecto - a rua - as linhas de investigação fundamental que se começavam a formalizar, muito por influência das matrizes dos investigadores. Nos textos que divulgavam os resultados do projecto, e que viriam a ser compilados em publicação com o mesmo nome por Stanford Anderson, surgiam abordagens, algumas assumidamente retrospectivas, outras mais prospectivas.

Dentro da primeira parte intitulada "Streets in the Past", Rykwert empreendia uma análise embrionária e etimológica da "rua"e Vidler recuava e estruturava uma historiografia da "rua", num arco temporal definido. Nas restantes contribuições, as linhas de investigação eram tendencialmente prospectivas. Passavam pela estrutura, através de Ellis, Schumacher e Caliandro; pelo significado, a partir de uma visão semiótica lançada por Agrest e Czarnowski; pelo social e humano, com as reflexões de Levitas, Winkel e Gutman; ou pelo contexto, com Anderson e Frampton.

Estas investigações, do tipo fundamental, eram rematadas por uma última parte, de tipo aplicado e de desenvolvimento. O capítulo "Demonstration Project" compilava a investigação operacional efectuada e as propostas de projecto decorrentes de um estudo de caso em Binghamton, Nova Iorque (Fig.9). A pesquisa numa fase pré-projecto passara tanto pela análise física como pela social. A recolha de dados de tráfego, circulação, densidade e cruzamentos, era complementada por dados provenientes de inquéritos aos residentes e à comunidade.

A contribuição final "Rethinking the Urban Street: Its Economic Context”, de Peter Wolf, exercitava uma análise sobre o potencial económico da rua urbana. $\bigcirc$ que prefigura a inclusão da análise económica, enquanto estudo sobre a condição de viabilidade/ exequibilidade para a implementação da investigação desenvolvida.

\section{Das ruas à Universidade}

$\mathrm{Na}$ conjuntura de uma crise de financiamento da universidade, urge inteligência crítica na mediação entre investigação fundamental e aplicada. A inserção dos estudos avançados deverá assim constituir-se não como uma ameaça, mas como uma oportunidade para uma investigação em diálogo com o projecto e contribuindo para uma

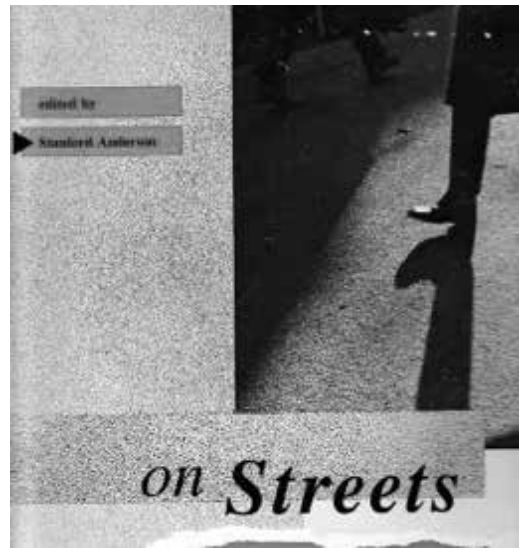

8. Capa do livro que publica o projecto de investigação On Streets.[Anderson, S. (ed.), 1991, On Streets, The MIT Press]

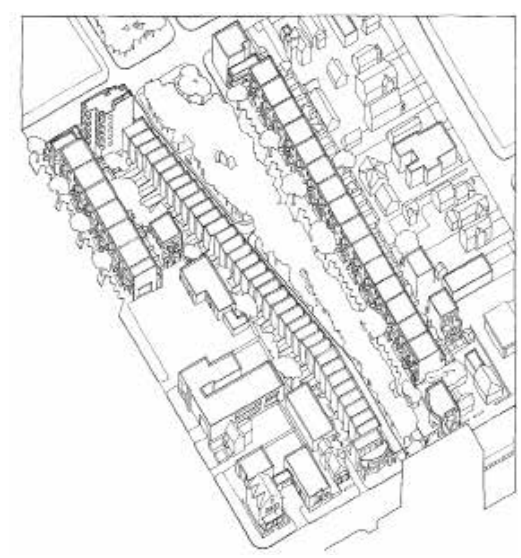

9. Axonometria do projecto para a Lisle Avenue. [Anderson, S. (ed.), 1991, On Streets, The MIT Press, p.374] 
ligação vertical, coerente, entre aprendizagem e profissão. Um misto de recherche patiante e impaciente, sábia num contexto de crescente relativismo e prevendo uma provisoriedade dos conceitos. Uma epistemologia, semelhante aos princípios da "Architecturologie" de Boudon (1971, p.2), mas ampliando o seu domínio, constituiria uma disciplina de um conhecimento rigoroso sobre o que documenta e alimenta a arquitectura, resistindo sempre à tentação de ser disciplinada.

\footnotetext{
$1 \rightarrow$ Noutro enquadramento, Hanrot (2002, p. 93) reorganiza a escala, admitindo

a investigação experimental como intermédia da fundamental e da aplicada.

$2 \rightarrow 0$ termo prospectivo foi introduzido por Gaston Berger e originou a publicação

que viria a editar, Prospective: "Elle est une reflexion sur l'avenir, qui

s'applique à en décrire les structures les plus générales et qui voudrait

dégager les elements d'une méthode applicable à notre monde en accelération"

(Berger, 1960).

$3 \rightarrow$ European Symposium on Research in Architecture and Urban Design, Paisaje

Cultural, Madrid, 16-19 Jan 2008.
}

\section{Referências}

Anderson, S. (ed.) (1991) On streets.

Cambridge, Mass.: MIT Press

-

Balandier, G. (1963) Reflexões prospectivas sobre as Ciências do Homem. Análise Social, I, 361-374

-

Baptista, L. S. (2008) "Delirious New York" explicado às crianças. Artecapital. http://artecapital. net. Consultado em Janeiro de 2012

-

Berger, G. (1960) Méthode et résultats. Prospective, 6

-

Bergson, H. (1975) Mémoire et vie. Textes choisis par Gilles Deleuze. Paris: Presses universitaires de France.

Boudon, P. (1971) Sur l'espace architectural. Essai d'épistémologie de l'architecture. Paris: Dunod

Damásio, A. (2010) O livro da consciência: a construção do cérebro consciente. Lisboa: Temas e Debates

-

Eisenman, P. (2008) EURAU - European Symposium on Research in Architecture and Urban Design. Madrid

Frank, S. (2010) IAUS, the Institute for Architecture and Urban Studies: an insider's memoir. Bloomington: AuthorHouse

-

Galison, P. (1990) Aufbau/Bauhaus: Logical Positivism and Architectural Modernism. Critical Inquiry, 16(4), 709-752

Girard, C. (1986) Architecture et concepts nomades: traité dsindiscipline. Bruxelles: P. Mardaga
Gropius, W. et al. (1970) New Ideas on Architecture. In Conrads, U. Programs and manifestoes on 20th-century architecture. Cambridge, Mass.: MIT Press. 46-48

Gropius, W. (1970a) Principles of Bauhaus Production. In Conrads, U. Programs and manifestoes on 20th-century architecture. Cambridge, Mass.: MIT Press. 95-97

-

Hacking, I. (1983) Representing and intervening. Cambridge: Cambridge Univ. Press.

-

Hanrot, S. (2002) A la recherche de l'architecture: essai d'épistémologie de la discipline et de la recherche architecturales. Paris: L'Harmattan

-

Koolhaas, R. (1994) Delirious New York: a retroactive manifesto for Manhattan. New York: Oxford University Press [1978]

-

Krüger, M. (2005) Leslie Martin e a Escola de Cambridge. Coimbra: e|d|arq

-

Kuhn, T. S. (2009) A Estrutura das Revoluções Cientificas. Lisboa: Guerra e Paz

-

Martin, L. (1958) Conference on Architectural Education. RIBA Journal, 65(8)

Martin, L. (1972) The Grid as Generator. In Martin, L.; March, L. (eds) Urban Space and Structures, Cambridge: Cambridge University Press, 6-27

Mello, D. C. (2007) A Arquitectura Dita: Anamorfose $\&$ Projecto. Doutoramento, Faculdade de Arquitectura da Universidade Técnica de Lisboa, Lisboa
Mendini, A. (ed.) (1971) The City as an Artifact Casabella, 359-360

Meyer, H. (1970) Building. In Conrads, U. Programs and manifestoes on 20th-century architecture. Cambridge, Mass.: MIT Press, 117-120

-

Phillips, S. (2009) Research Practice Symposium. AeDPress

-

Picon, A. (1999) Architecture, Science, and Technology. In Galison, P.; Thompson, E. (eds.) The architecture of science. Cambridge, Mass.: MIT Press. 309-336

Portas, N. (2008) A arquitectura para hoje; finalidades, métodos, didácticas.

Lisboa: Livros Horizonte

-

Simon, H. (1991) Bounded Rationality and Organizational Learning. In Organization Science, 2 (1), 125-134

-

Snow, C. P. (1961) The two cultures and the scientific revolution: the Rede lecture 1959. Cambridge

-

Viollet-le-Duc, E.-E. (1879) Histoire d'un dessinateur, comment on apprend à dessiner. Paris: J. Hetzel 